\title{
Paideusis
}

\section{Bernard Lonergan and Education}

\section{Hugo Meynell}

Volume 7, Number 1, 1993

URI: https://id.erudit.org/iderudit/1073284ar

DOI: https://doi.org/10.7202/1073284ar

See table of contents

Publisher(s)

Canadian Philosophy of Education Society

ISSN

0838-4517 (print)

1916-0348 (digital)

Explore this journal

Cite this article

Meynell, H. (1993). Bernard Lonergan and Education. Paideusis, 7(1), 3-13.

https://doi.org/10.7202/1073284ar

(C) Hugo Meynell, 1993

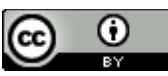

This document is protected by copyright law. Use of the services of Érudit (including reproduction) is subject to its terms and conditions, which can be viewed online.

https://apropos.erudit.org/en/users/policy-on-use/ 


\section{Bernard Lonergan and Education}

\section{Hugo Meynell, University of Calgary}

The thought of Bernard Lonergan, though not yet as well known as it deserves, is of importance for a number of fundamental human concerns, and none more so than for education. In what follows, I shall try to show why.

Education, I think it would be generally agreed, is a matter of imparting both knowledge, and the dispositions which will enable pupils to acquire more knowledge for themselves. But what is knowledge, and what are the dispositions by which one acquires it? Is knowledge any more than the stock of opinions which hold most prestige in one's society, and which it is most inclined to promulgate? There is a suggestion in Plato's Theaetetus that knowledge is true opinion backed up by good reasons." But are not "truth" and "good reasons" fundamentally a matter of what any society says that they are? We might expect an educated person to have some capacity to criticize the conventions and assumptions of those among whom she lives. But if there are no transcultural norms of knowledge and value, what can such criticism amount to but the arbitrary replacement of one set of norms by another? Yet, if there were transcultural norms, how could we, as beings determined through and through by the cultures and societies in which we live, have any apprehension of them?

It cannot be said that people in general, including educationists themselves, have a very clear or critically-based notion of what education is, what it ought to be, and why. Assistance on this matter might be expected from the philosophers; but it is questionable-to say the least-whether much help is actually to be had from this quarter. A few decades ago, positivism was in the ascendant; on positivist assumptions, the sciences, whose conclusions could be verified by sense experience, were knowledge properly speaking, and other supposed kinds of knowledge were reducible to subjective attitudes or traditional prejudice. It has been widely acknowledged in the last couple of decades or so that positivism is mistaken, largely because it is self-destructive. You cannot verify by experience the proposition, that all propositions which have a claim to truth, but which are not true by definition, must be verifiable by experience; and the proposition does not appear to be true by definition.

Since the demise of positivism, there has been a growing consensus among philosophers that the foundations of knowledge are the objects of a fool's errand. Some propositions of fact and some judgments of value are more highly esteemed in a society than are others; why they are so is a matter for the social scientist to study. The methods by which socially-esteemed systems of propositions are, as a matter of fact, justified, equally determined by social consensus; any appeal to absolute standards of what is true or false, good and bad, is simply a matter either of uncritical dogmatism or outmoded superstition. ${ }^{2}$

I think that most educationists worth their salt would wish to put their students in touch with principles by means of which they are able to criticize the factual and moral errors or prejudices of those among whom they live; and, if necessary, of the whole society of which they form a part. But if the account of the matter which I have just sketched is correct, there are no such standards. It should be obvious, of course, that this position is every bit as self-destructive as positivism, as well as leading to other absurdities. One would have thought that 
"Mercury is liquid at normal temperatures at the surface of the earth" is true if, and only if, mercury is liquid at normal temperatures on the surface of the earth. But mercury would have been liquid at these temperatures even if humanity had never evolved, let alone discovered this fact to be the case. And what at this rate is to be made of the supposed truth, that truth and goodness are merely matters of social convention? Is this only a matter of social convention? If it is, one might just as well replace it with another social convention-say, that truth is whatever agrees with the doctrines asserted in Capital or The Koran-if one has oneself sufficient power or prestige to get away with it. If it is not supposed to be a matter of mere social convention, then the view that truth is always and inevitably merely a matter of social convention is thereby falsified.

Bernard Lonergan's longest work, and in my opinion his greatest, is entitled Insight: A Study of Human Understanding. ${ }^{3}$ What does Lonergan mean by "insight?" Basically, it is that which concludes the tension of inquiry about anything, when one is suddenly inclined to say, "I've got it!". It is something which occurs often in the intelligent and seldom in the stupid. Insights can be had about any topic, from matters of common sense to the most recondite questions of science. An answer may occur to me about something which is puzzling in the sounds made by the engine of my car, or about some problem in quantum mechanics. Classic examples of the arising of insights from patterns of experience are provided by the the use of diagrams to facilitate grasp of the proof of theorems in Euclidean geometry.

An insight in Lonergan's sense is not necessarily the correct solution to the problem in response to which it arises. I may gain an insight to the effect that my neighbour is angry from the expressions on his face, which I learn later was mistaken; it may turn out that he was only pretending, or that his face was just made that way. For Lonergan, coming to know consists essentially of three components, of which insight in the sense which $I$ have mentioned is only one. There is the experience which gives rise to questions; there is the understanding which envisages (through insight) possibilities that may account for the experience; and there is the judgment which affirms that one of these possibilities is probably or certainly correct. It is one thing for me to see or hear certain features of your behaviour; another to grasp from them the possibility that you may be angry; and yet a third to affirm that you actually are so.

Lonergan relates understanding and judgment to the asking of questions. Questions relating to understanding are such that they can never appropriately be answered "yes" or "no," whereas questions relating to judgment can often be so. (Lonergan distinguishes in this context between "questions for intelligence" and "questions for reflection.") If a schoolmaster comes into a classroom, and asks what is the explanation for the loud explosion of laughter with which he is greeted, or for the white mouse peeping out of his desk, it would be inappropriate, to a degree approximating to insubordination, for a student to answer "Yes" or "No." Some possible explanation bas to be offered first-for example, that the master has inadvertently put on two ties, or failed to remove the shaving soap which he had applied to his face earlier that moming; or that Massingbourne Minor has brought the animal to provide distraction from the tedium of the curriculum. Once such an explanation has been offered, the further question can be asked and answered of whether it is correct, and the answer "Yes" or "No" may then be appropriate. 
One more basic type of mental act has to be distinguished, that of decision. It is one thing to judge that something is so, whether this is a matter of fact or value, but another for me to decide to act accordingly. I may fail to do so, through laziness, cowardice, or addiction to my pleasures. On the other band, for me to attend carefully to my experience, to envisage as many possibilities as I can, and judge strictly in accordance with the evidence, may involve an important decision on my part-say, if my friends or my employers are keen that I should accept their biased judgments on some issue rather than making up my own mind. Lonergan by no means denies that we have to accept authority in many matters. ${ }^{4}$ Indeed, the common claim that we ought not to do so can easily be shown to be absurd. All of us accept authority many times a day. We all know the shape of the United States; but how do we know it? The surveyors, as Lonergan says, believe one another; and the rest of us believe the surveyors. ${ }^{5}$ However, we have to exercise reasonableness in accepting some authorities rather than others, and in recognizing in each case what the limits of those authorities are.

In writings subsequent to Insight, Lonergan distinguished four "transcendental precepts" ("transcendental" as applying to all areas of human concern whatever) corresponding to his four basic types of mental activity: "Be attentive" (to experience), "be intelligent" (in hypothesizing or envisaging possibilities), "be reasonable" (in taking care to judge always strictly in accordance with the available evidence), and "be responsible" (in deciding to act accordingly). ${ }^{6}$ The fundamental answer to the question about the nature and aims of education can now be given in summary form: it is the very essence of education to promote in those educated the capacity to exercise the four transcendental precepts.

Somebody might ask, "Why should we believe that people really have these mental capacities at all, let alone that they are essential to education? Indeed, is not the supposition that people really are capable of acting in these ways a relic of pre-scientific superstition, since we now know that buman beings are nothing other than more or less elaborate physical and chemical machines?" Lonergan insists that people must really be capable of such mental activity, whatever positivists and behaviourists have to say about the matter, and supports his claim by an argument which is as amusing as it is devastating. The denial that they occur, or that one uses them oneself, is actually self-destructive. Suppose someone does deny that one tends to get to know what is so by being attentive, intelligent, and reasonable. Either she says this on the ground that it gives the best available account of the relevant evidence, or she does not. In the former case, she has exercized the basic set of mental capacities distinguished by Lonergan in the very act of denying that anyone does so. If she does not-if what she says is neither said for good reason, nor offered for the acceptance of others on the basis of appeal to their reason-what is the point of listening to her? As to responsible decision, to say something on the grounds that there is good reason for saying it is itself a responsible act.?

When first confronted with the question of what it is to come to know, one may be inclined to say that it is really just a matter of attending to experience, or, as Lonergan puts it, of "taking a look."8 According to Lonergan, this assumption is not only erroneous in itself, but a veritable cornucopia of other errors. What does the error amount to, and why is it plausible? Suppose I am 
asked whether there is a Trumpeter Swan in the Calgary Zoo, and I do not know whether there is one or not. If I do not know, it may be that I have no opinion whatever on the subject; or I may believe that there is or that there is not, but lack the degree of certainty which would make such a belief (if true) count as knowledge. But in either case, the obvious way of turning ignorance or merely tentative belief into knowledge in this instance, as in countless others, would be to take a look. Taking a look, one might say, is what is most obvious in coming to know. But perhaps we should not be too hasty to infer that, as Lonergan puts it, what is obvious in knowing is what knowing obviously is. ${ }^{9}$ Other activities may be involved, as indeed turns out to be the case when one considers other examples of what it is to come to know.

What about my knowledge of what another person is thinking or feeling? Suppose one of the members of a lecturer's audience is thinking, "How bored I am. I wonder when the lecturer will stop?"' How could the lecturer himself, or another member of the audience, come to know this? Well, people can look and sound bored; for example, they can yawn, frown, stretch, and fidget. But one's thoughts and feelings seem, at first sight at least, to be something over and above the publicly observable facts by which one may express them. Does this mean that they must for ever be unknown to other persons? Here we stumble over one of the most notorious problems of philosophy, that of other minds. How can I ever come to know the contents of other minds than my own? How do I know that other people even have minds, that other bodies like my own are centres of consciousness, and not just very complicated machines? Reflecting on the problem of how we think we know, at least, what other people are thinking and feeling, we come upon the components of knowledge which are other than taking a look, or any kind of attention to the objects of our senses. I may understand various possibilities as to what you may be thinking or feeling; and I may judge that one of them is confirmed against the others by what I can observe of your speech and behaviour. Coming to know in this case clearly is a matter of going beyond mere experience.

Two other examples of our coming to know will provide further elucidation of the point. Contemporary physicists believe in an apparently everincreasing number of types of fundamental particle. This is not because electrons, positrons or neutrinos have ever been observed, have ever-or, indeed, could ever-become direct objects of experience. (Their existence is, of course, verified in experience, as the best way of accounting for it; but that, crucially, is another matter.) The fact is that science does not consist merely in the heaping up of quantities of records of observations and experimental results; it involves intense creative theorizing, and fundamental particles have come to be known only as a result of this. There is a story about a prospective graduate student in theoretical physics who asked his professor what equipment he would need. The professor answered, "A lot of pencils, quantities of paper, and a large waste-paper basket." As far as these intellectual aristocrats are concerned, the actual business of gathering evidence is left to the hod-men in the laboratories. The pencils and paper are needed for theoretical creativity (which takes place at the level of what Lonergan calls "intelligence'), the waste-paper basket for all the theories which turn out to be wrong once the relevant evidence has been marshalled (at the level of what he calls "reasonableness"). Thus, the story is a rather forceful illustration of the two other components of coming to know on 
Lonergan's account, apart from attending to evidence in experience. Not, of course, that the vital role of amassing observations in science should be underestimated: Tycho Brahe had patiently to collect and record his observations of the planets before Kepler could discover his famous laws by insight into them. The making and recording of observations is a necessary part of science; the crucial point is just that it is not the whole of it.

I said that the belief or assumption that knowing was just taking a look was, in Lonergan's view, the error of errors. On the subjects of other minds and physics, there are two influential theories which depend on it, those of behaviourism and operationism. An academic psychologist might insist that the thoughts and feelings of other persons, at least as usually conceived, cannot be real, or cannot at least be of significance or concern to the scientist, because they are not able to be observed. What is real is only the visible gestures and audible noises that they make, and the underlying physical and chemical processes which we could observe if we cut the open their heads or planted electrodes in them. This behaviourist view derives from the false assumption that knowing is really a matter of taking a look, together with the true belief that we can get to know what other people's thoughts and feelings are. It is, of course, notorious that this view-which on Lonergan's account is based on nothing better than a fundamental blunder about the nature of knowledge and, therefore, of science - has dominated academic psychology for several decades. ${ }^{10}$ According to "operationists," who are to physics what behaviourists are to psychology, electrons, positrons, and so on are not real because they are not observable; they are to be taken as merely convenient theoretical fictions for anticipating and manipulating, or operating upon, what is so observable.

But there is a third category of what would at least usually be accepted as knowledge, consideration of which seems to bring out once and for all the absurdity of the view that knowledge is fundamentally just a matter of taking a look. We cannot observe the things and events even of the recent, let alone of the remote, past; yet, we can apparently come to know about Abraham Lincoln or Pericles, or even the organisms which inhabited the sea in the Precambrian era. Whatever the difference between our historical inquiries on the one hand, and those into other minds and physics on the other, we find that just the same basic principles are to be applied; we attend to experience, envisage possibilities as to what may be so, and judge that some self-consistent set of these probably is so. Now, whatever may be the case about elementary particles and the thoughts and feelings of other persons, it does seem as clear as it could well be that a person or event of the remote past is one thing, the evidence for it available to the present- day investigator another. Marks on documents available in our libraries, and noises emitted by twentieth-century professors of medieval history, may be the only sources in our experience for knowledge of Frederick Barbarossa; but they are not Frederick Barbarossa. It must be admitted that few have actually taken the underlying prejudice so far as to draw the inference that they are; 11 yet this would inevitably follow from the basic principle underling behaviourism and operationism, that knowing is in the last analysis just taking a look, and that we consequently cannot really come to know what we cannot take a look at.

One of the bogies which is apt to haunt a scientific civilization is the suspicion that we might ourselves one day be explained away as just compli- 
cated physical machines with our pretensions to thought, speech, and action on the basis of reason exposed as illusions. But it may be seen from what $I$ have already argued that, on Lonergan's view, it is inconceivable that science should prove, or even render remotely possible, any such conclusion. If it did, it would fatally undermine its own foundations. Why do we rightly accept, by and large, what scientists tell us about the subjects which they study, rather than the claims of witch-doctors, shamans, or persons of common sense? It is only on the assumption that the scholarly communities of which they are members have exercized attentiveness, intelligence, and reasonableness on the relevant topics to a unique degree. If science were to "disprove" the existence, or the efficacy in speech and action, of these basic metal capacities, it would destroy itself. If we were all "just machines," we could only think or say that we were "just machines" through physical and chemical causation, and not because we had good reason to do so.

There is something of a groundswell in contemporary thinking, both among certain types of academics and among ordinary people, to the effect that there is something very wrong both with naive realism and with the popular scientific world-view; that they both conspire to cramp, corrupt, and discourage the human spirit, and, furthermore, somehow misrepresent the real nature of things. Appeal is often made in this connection to contemporary physics, oriental mysticism, or even some amalgam of the two. ${ }^{12}$ While these tendencies evidently provide a useful corrective to naive realism from a point of view such as Lonergan's, they are worrying so far as they tend to issue in rampant subjective idealism, which effectively denies the reality of a world independent of our thought, or (as more usually happens) in ways of thinking which would lead to such subjective idealism if they were carried through consistently. If the physicist causes a photon to exist in the process of observing its alleged effects, where is the process of subjective creation to stop? If the ultimate constituents of "reality," such as photons are supposed to be, are in the last analysis figments of our minds, what aspect of "reality" is not such a figment, especially if one is convinced that naive realism provides no safe stopping-place? The sinister application of these assumptions to history were delineated by George Orwell in Nineteen Eighty-Four; why should we bother to try to get the facts of the past right, when there is no other "past" than whatever is made of the data by the ideological group to which we happen to belong? The fact is that a distorted conception of the ideal of objectivity, such as one finds in naive realism, positivism or behaviourism, inevitably provokes a subjectivism in revolt against it. When carried through consistently, such an attitude is, perhaps, even more deplorable than the attitudes to which it is opposed. But on Lonergan's account, "genuine objectivity is the fruit of authentic subjectivity,"13 in other words, of thoroughgoing attentiveness, intelligence, and reasonableness. At this rate, conviction of the reality of the world, rigorous science, and enhancement of the life of the human spirit can be mutually reinforcing rather than destructive ideals. The philosophical idealist or sociological relativist is quite right in insisting that creative acts of mind ("insights") are required in order that we may come to know the world, but wrong in inferring from this that the world is really created by such acts of mind. In Lonergan's own terms, the idealist emphasizes the role of intelligence, but neglects that of reasonableness in the business of coming to know about the real world. 
Lonergan's thought has at least as much bearing on ethical and political problems as it has on our knowledge of matters of fact. For all their general opposition to one another, science as popularly conceived, on the one hand, and ways of thinking which champion authentic subjectivity, such as existentialism, on the other, are at one in implying that value judgments are quite arbitrary in the last analysis. But for Lonergan, theoretical reason and practical or moral reason are closely allied. In the case of moral reasoning, evidence on people's needs and feelings is what is of special relevance. Now, not only may my own immediate needs and interests conflict with my long-term needs and interests, but the needs and interests of myself or my group may conflict with those of the majority of people. To adapt a well-known slogan, the interests of General Motors may in a particular instance not be identical with the interests of the USA, and, indeed, the interests of the USA may not be identical with the interests of humanity at large. In such cases, individuals and groups have motives for self-deception, and for what Lonergan calls "the flight from insight."14 Suppose I am a school-teacher who takes pleasure in punishing his students; I will then have any number of reasons for failing to admit this to myself. I will probably be inclined to put it to myself, on the contrary, that I dislike punishing them, and only do it for their own good, or so that discipline may be preserved in my class. I will be liable to brush aside any evidence that my motives are not as I would wish them to be, and to react with contempt, anger, or even threats to any suggestions made by others to this effect. Inability to attend properly to one's own emotions and feelings has been generally recognized since the time of Freud to be a prime cause of mental illness; and to attend to them, however disagreeable or painful it may be to do so, to be the only way to mental health. One application of Lonergan's thought is to show how the babel of conflicting theories and jargons excogitated by Freud and his followers could be revised and set up on a more self-consistent basis. ${ }^{15}$

If the Freudians have been specially informative about the flight from insight as it affects the life of the individual, its social and political consequences have been extensively set out by the Marxists. According to them, a group or a class may be in the grip of "ideology" so far as what it believes about itself, other groups, and the world, is determined rather by its self-interest than by objective consideration of the relevant evidence. If my own racial group enjoys its high standard of living as a result of exploiting the labour of another racial group, I may well be inclined to persuade myself of the view that members of the latter group are congenitally unable to appreciate the refinements of the life that I lead myself, or that they are perfectly happy with their inferior and exploited status. Still, though Lonergan admits a debt to Marx, he certainly goes beyond him. On Marxist principles, it seems far from clear why the worldview of the proletariat should be any less "ideological," any less subject to distortion through class prejudice, and any more liable to represent the actual truth about the world than that of the bourgeois capitalist. For Lonergan, the criterion is absolutely clear. A group or class is dominated by "ideology" in the abusive sense so far as it restricts, rather than fosters, the attentiveness, intelligence, and reasonableness which lead to knowledge of the real world and of what is really right in morality and politics.

It is characteristic of our culture that we seem to be caught in an insoluble dilemma about the nature of morality, between a rigid and insensitive absolutism 
which makes no allowance for special circumstances and cases on the one hand, and a thoroughgoing scepticism, and relativism, on the other. Many of us get by on an inconsistent compromise between these two positions. Perhaps one of the worst consequences of the error that knowledge is a matter of taking a look, is the conviction that there is no knowledge to be had of any "real" good and bad, right and wrong, since these are evidently not "out there" to be looked at. There is a firm flexibility in Lonergan's account of ethics which recognizes the relativity of many particular rules to specific situations, while by no means either capitulating to scepticism or relativism or resorting to inconsistent compromises. In quite large measure, we will find that different laws and customs are really for the best in different societies, owing to their differing traditions and material and economic circumstances; but this by no means impugns the objectivity of the underlying moral principles to be derived from the transcendental precepts. And in directing and ordering societies, we have a clear criterion for articulating the difference between progress and decline. ${ }^{16} \mathrm{~A}$ declining culture is torn more and more by conflicting ideologies, where each group attends, understands, judges, and decides only in its own interest rather than according to the actual available data and in the general interest. Progress is a matter of ever fuller implementation of the four basic precepts-to be attentive, to be intelligent, to be reasonable, and to be responsible in all areas of life, and especially where this goes against one's own bias or that dictated by the groups of which one is a member.

What of our knowledge of cultures widely different from our own, the kind of thing aspired to by the historian or anthropologist? There are two extreme views on this matter, between which Lonergan's views provide a kind of Hegelian synthesis. According to one view, the self-understanding of what we are pleased to call "primitive societies" is completely irrelevant to a correct understanding of those societies. According to an account more recently fashionable, on the contrary, the anthropologist misconceives her task if she sees it as anything other than recovering and reproducing the society's own self-understanding. ${ }^{17}$.The latter view has arisen as a very understandable reaction against Western cultural imperialism, which, it is not unreasonably felt, has too easily and contemptuously dismissed rival worldviews as so much primitive superstition. The conviction has, thus, got about that each society has its own "world" and its own type of "rationality," and that none is intrinsically preferable to any other, as on the relativist view which I mentioned earlier in this paper.

In accordance with Lonergan's account, the scientific worldview is very powerfully corroborated.within its limits; what does that worldview amount to, after all, but the result of sustained application of attentiveness, intelligence, and reasonableness to important aspects of reality? However, it by no means follows from this that cultures alien to our own may not sometimes have their good points from which something is to be learned. As Lonergan sees it, both the natural and the human sciences have $a$ priori assumptions; the former, to the effect that everything is amenable to theoretical explanation; the latter, that every product of the human spirit is due to some combination of attention and inattention to experience, understanding and lack of understanding, judgment and failure to judge. Such lacks and failures may characterize the anthropologist's own view of things as much as that of the society which she is 
studying. On the other hand, so far as the views of themselves maintained by members of an alien culture are due to attentiveness, intelligence, and reasonableness, they are to be accepted by the anthropologist; to the degree that they fail to do so, it is up to her to provide a more adequate account. Even in the most primitive society, practical needs will ensure that a broad range of judgments are correct on issues relevant to the immediate business of living; a society of which the members are not to quite a large extent attentive, intelligent, and reasonable will hardly survive in the jungle or the desert. On matters not immediately testable in this practical way, societies tend to follow their feelings in forming their beliefs, and to think in terms of powerfully moving images and stories. So there arise the great myths whose hold on civilisation is such a striking feature of human history. ${ }^{18}$ The critique of myth can begin only when human beings begin to develop that power of abstract thought which is the special legacy of the ancient Greeks. Then people start asking such questions as: Is it really reasonable to suppose that the stories of the gods which our ancestors have told us are true? Or, should we believe rather that they have either been mistaken in good faith on these matters, or that they have deceived us? So, bit by bit, rational principles begin to be applied to the whole beliefsystem of a society with results which must ultimately be fatal to religion, if many of our contemporaries are to be believed. ${ }^{19}$

But however much a culture is, or claims to be, dominated by rationality, the emotional needs met by myth still remain; what this means for human destiny and what is to be done about it becomes clear when one approaches the question of Christianity and its credentials from Lonergan's perspective. Since the time of David Hume and Immanuel Kant, it has been very widely supposed that there are no sound arguments for the existence of God, though the traditional "proofs" have retained some vogue among Roman Catholics. Protestants have been wont to appeal to faith as opposed to reason; but their atheist opponents have not unreasonably suggested that this is little more than a desperate expedient to shore up a position admitted to be rationally indefensible. Lonergan admits that faith in God is seldom arrived at simply as a result of rational argument; yet, he insists, in accordance with the traditional Catholic view, that there are sound reasons for believing in God, and that the rigorous and diligent application of the transcendental precepts will tend to issue in religious faith. According to him, the world is nothing other than what is to be conceived and affirmed on the basis of our experience, and is as such intelligible; and the best ultimate explanation for such a world is that it is the work of an infinite Mind, which conceives and wills it in its entirety rather as we conceive and will our own comparatively insignificant actions and products. ${ }^{20}$ The counter-arguments of Hume, Kant, and their successors can all be shown to depend on inadequate theories of knowledge.

But even if we have compelling reason to affirm the existence of God, we must also acknowledge that there is a problem of sin which ravages human individuals and communities. For persons and groups by no means always think or act attentively, intelligently, reasonably, or responsibly; they are very often self-deceiving and not seldom malicious, and evil gives rise to more evil in a descending vortex of hatred, misrepresentation, and violence. How could this problem be met? God might decide simply to wipe out the human race in the manner described by the story of Noah's flood in the Book of Genesis; but this is 
not God's way. Within the scientific worldview as it has been since the midnineteenth century, we contemplate a series of levels of reality, each depending on an order maintained at the lower levels. Thus, the level of elements and compounds studied by the chemist depends on the level of fundamental particles studied by the physicist; the level of animal and plant life on both of these; and the specifically human level of rational thinking and living on all three. (The properties of being on each of these levels are to be grasped by intelligence and affirmed by reason on the basis of evidence in experience.) To maintain the order of the universe as just described, God would have to act in such a way as to raise the fitful and wayward reasonableness and responsibility of human beings to a higher level, rather as God raises the physical to a higher level in the chemical order of reality, the chemical in the biological, and so on. How might this be done? An actual history could be provided which has the emotional and symbolic properties of myth. By participating in this true history through recitation and ritual, we will gradually be enabled to harness our affections and redirect our aggressions in such a way as to bring human life to the full excellence of which it is capable. As Thomas Aquinas remarked, grace does not take away nature, but perfects it. ${ }^{21}$

To sum up the whole matter: the essence of education, in Lonergan's view, is nothing other than to foster attentiveness, intelligence, reasonableness, and responsibility to the uttermost. The judgments current in our society or any other, whether matters of common sense, science, or value, are to be affirmed not as unquestionable dogmas, but simply as the best that attentiveness, intelligence, and reasonableness have come up with thus far, clearly, there is more evidence to be attended to and more hypotheses to be envisaged which will, in time, render many of these judgments liable to modification or even outright rejection. Education in the arts and humanities is apt to keep consciousness open and flexible by way of expanding it through the realization of how others have understood, judged, and decided. The doctrines of religion are to be commended as fully in accordance with reason while, indeed, going beyond what unaided reason could find out for itself; even though (in certain privileged cases) the authentic exercise of the human mind confirms that they are never to be rejected, one may advance indefinitely in understanding and applying them.

\section{Notes}

1200 e, 202c, 210 a-b.

${ }^{2}$ For an influential and powerful exposition of this view, see Richard Rorty, Philosophy and the Mirror of Nature (Princeton, NJ: Princeton University Press, 1979).

${ }^{3}$ Bernard Lonergan, Insight: A Study of Human Understanding (London: Longmans, Green, and Company, 1957). It has recently been reissued as Volume 3 of Lonergan's Collected Works (Toronto: University of Toronto Press, 1992).

${ }^{4} \mathrm{Cf}$. Insight, 703-18.

${ }^{5}$ Method in Theology (London: Darton, Longman and Todd, 1972), 42.

${ }^{6} \mathrm{Cf}$. Method, 20, 53, 55, 231-32.

${ }^{7}$ Cf. Method, 16-17. 
${ }^{8} \mathrm{Cf}$. Insight, 253, 412-16, etc.

9 Insight, 416.

${ }^{10}$ Its most impressive and systematic exposition is probably due to B.F. Skinner; see especially his Science and Human Behavior (New York: The Free Press, 1953).

${ }^{11}$ But cf. the end of Chapter 5 of A.J. Ayer's Language, Truth and Logic (London: Gollancz, 1946).

${ }^{12}$ Cf. F. Capra, The Tao of Physics (Berkeley, CA: Shambala, 1975).

${ }^{13}$ Method, 265, 292.

${ }_{14}^{14}$ Insight, xi-xii, 191, 199-203.

${ }^{15} \mathrm{Cf}$. Insight, Chapter VI.

${ }^{16} \mathrm{Cf}$. Insight, xiv, $231,742$.

${ }^{17} \mathrm{Cf}$. the work of Peter Winch, especially The Idea of a Social Science (London: Routledge and Kegan Paul, 1958), and "Understanding a Primitive Society" in D.Z Phillips (ed.), Religion and Understanding (Oxford: Blackwell, 1967).

${ }^{18}$ On myth, cf. Insight, 539-47.

${ }^{19}$ Insight, 543-7, 561-2.

${ }^{20}$ Insight, Chapter XIX; Method, p. 101.

${ }^{21}$ For this argument for the truth of Christianity, cf. Insight, Chapter XX. In Method, Chapter 4, it is emphasized that elements of authenticity and inauthenticity are to be found in all religions, and it is argued that the grace of God is active in all of them so far as they promote human authenticity. 